\title{
Lady Macbeth: ambição e loucura
}

\section{Lady Macbeth: ambition and madness}

\author{
Aline Tayná de Quadros Kaveski*
}

\begin{abstract}
Resumo: O presente estudo analisa a personagem Lady Macbeth da obra teatral intitulada Macbeth, de William Shakespeare. A análise aborda as características psicológicas da coprotagonista, que proporcionam a ela uma forte influência na decisão inicial do marido de matar o rei e tomar para si o trono, mas que, num determinado ponto da peça, fazem-na sucumbir até o suicídio. São levantadas algumas hipóteses sobre por que a personagem, mesmo depois de alcançar o que ambiciona, entra em derrocada. Uma das hipóteses é que ela não consegue lidar com a própria consciência e com o segredo do assassinato e enlouquece. Outra hipótese, proposta por Freud, é a de que Lady Macbeth desilude-se quando não consegue dar sucessores ao trono para seu marido. Para Bloom, é o afastamento sexual do casal que provoca a desilusão de Lady Macbeth. Esse artigo discute todas essas possibilidades.
\end{abstract}

Palavras-chave: Shakespeare. Lady Macbeth. Ambição. Loucura.

Abstract: This study examines the character Lady Macbeth of the play entitled Macbeth by William Shakespeare. The analysis focuses on the psychological traits of the character, that give her a strong influence on her husband's initial decision to kill the king and take the throne to himself, but that, at a certain point of the play, makes the character succumb and commit suicide. Some hypotheses are proposed about why the character, even after attaining what she longed for, breaks down. One hypothesis is that the character cannot deal with her own conscience and the secret of the murder and goes insane. Another hypothesis, proposed by Freud, is that Lady Macbeth is disappointed when she cannot give her husband successors to the throne. To Bloom, it is the sexual estrangement between the couple that causes Lady Macbeth's disappointment. This article discusses all these possibilities. Keywords: Shakespeare. Lady Macbeth. Ambition. Madness.

\section{Introdução}

Neste trabalho analisarei a influência que um personagem coprotagonista pode exercer sobre o protagonista de uma peça teatral. Para tal, examinarei as ações da personagem Lady Macbeth da tragédia Macbeth, de William Shakespeare. A análise abordará, principalmente, as características psicológicas da personagem, as quais desencadeiam atos seus e de seu marido que alcançam proporções e desfechos não esperados. Este gênero de peça teatral - a tragédia - é composto por um número considerável de personagens

\footnotetext{
* Especialista em Língua Portuguesa e Literatura. Instituto de Estudos Avançados e Pós-Graduação, ESAP, Brasil. E-mail: <aline.tayna@bol.com.br>
} 
que, segundo Aristóteles, agem conforme o próprio caráter e pensamento, com os quais "tem origem a boa ou a má fortuna dos homens". (2001, p.448).

A escolha da personagem Lady Macbeth para análise tem o propósito de identificar os artifícios utilizados por ela para influenciar na decisão do marido de matar o rei, alcançando assim seu próprio desejo de se tornar rainha. E, ainda, entender - se possível - por que, mesmo depois de realizado o desejo, ela enlouquece e se suicida.

Para analisar esta personagem trarei como apoio reflexões de autores que teorizam sobre a causa da queda da personagem, que, segundo eles, ocorre pela limitação de imaginação que ela demonstra. Trarei também análises que defendem a ideia da infertilidade como algo que possibilita a desagregação psíquica de Lady Macbeth. Mas tendo em vista que nenhuma interpretação pode afirmar-se como definitiva, mencionarei também outras análises sobre o possível motivo da desilusão da personagem em estudo.

Todavia, para melhor conhecimento da personagem, farei uma breve descrição da participação de Lady Macbeth na peça.

\section{Lady Macbeth: a trágica heroína}

Shakespeare criou, como em outras tragédias, um quadro sociopolítico onde seus personagens buscavam as mais variadas formas de poder, e em Macbeth essa sede de poder é o tema fundamental. Na primeira parte da peça isso fica enfatizado em personagens secundários e na coprotagonista Lady Macbeth, que é contagiada com a exaltação do marido e, com entusiasmo, apoia sua ambição.

A primeira metade da obra é maior que a segunda, e ela é dominada por Lady Macbeth, que exerce uma influência decisiva sobre a ação. Mas o autor a retira do foco após a quarta cena do terceiro ato, voltando ela a aparecer, brevemente, no início do quinto ato, já em estado de loucura.

A personagem compartilha vários traços de personalidade com o marido: ambos são dotados de temperamento altivo, soberbo e imperativo; são arrogantes e desprezam seus inferiores; seus objetivos são posição e poder. E contrastam em outros pontos: ela é dotada de uma inabalável firmeza de espírito, mostrando-se capaz de submeter a imaginação, as emoções e a consciência. Para Bradley (2000, p.268), Lady Macbeth é um "demônio 
inabalável" e para Barbara Heliodora, "ela é um complemento de Macbeth, a parte negativa da sua ambivalência" (2004, p. 171), o que a autora chamou de "consciência do mal".

Para a personagem de Lady Macbeth não há distinção entre vontade e ato; as profecias das bruxas de que Macbeth seria Senhor de Glamis e de Cawdor e Rei da Escócia se tornam determinação. A personagem conhece bem a fraqueza de seu marido e opõe-se à "bondade humana" dele nas primeiras cenas, e, encontrando-se num estado de euforia, diz em solilóquio:

[...] tenho medo da tua natureza: ela está muito cheia do leite da bondade humana, para encurtar caminho. Tu quererias ser grande; não deixas de ter ambição, mas não possuis a malvadez que a deve acompanhar. A grandeza a que aspiras desejarias alcançá-la virtuosamente. (SHAKESPEARE, Ato I, Cena V, 18-23).

Prevendo os acontecimentos que viriam, ela nega o próprio sexo, invocando os espíritos do mal para evitar que sua fragilidade feminina interviesse na sua decisão de instigar seu marido no que fosse necessário para alcançar seus objetivos - matar o rei da Escócia, tornando-se, assim, ele mesmo rei. Para mim e para outros autores, é neste momento que Lady Macbeth instaura seu infortúnio, causado pela sua falta de imaginação e pelo fato de que, "ao mexer com essa força (espíritos do mal), os seres humanos sequer imaginam do que serão capazes e quais as consequências desse ato" (BRADLEY, 2009, p. 20), como veremos mais tarde.

Mesmo seus argumentos sendo intensos, eles não convenceriam Macbeth se este não tivesse vontade de executar a ação, mas o medo e o sentimento de injustiça o impediam, ou pelo menos, retardavam o plano. Lady Macbeth convence-o de que o ato é heroico, ignorando o fato de ser cruel e desleal. Faz provocações com a covardia do marido e por último apela ao amor dele por ela: "A partir deste momento farei pouco caso do vosso amor". (Ato I, Cena VII, 48-50).

Macbeth ainda teme que a tentativa de assassinato falhe e ela the responde de pronto: "Se o nosso golpe falha?! Atarraxai somente a vossa coragem no lugar devido, e não nos sairemos mal" (Ato I, Cena VII, 79-81); Macbeth, então, retruca com uma frase que descreve a atitude resoluta de sua esposa: "Só dás filhos à luz! Porque da tua substância implacável apenas se podem formar machos". (Ato I, Cena VII, 97-98). Lady Macbeth se incumbe 
de pôr drogas nas bebidas dos camareiros do rei e avisar Macbeth de que o caminho está livre para o assassinato. Ele fica admirado com a objetividade e o destemor da mulher, que não pensa nas consequências do ato e somente tem olhos fixos na coroa, e, num momento de entusiasmo, toma a decisão: "Estou resolvido; vou armar todas as minhas forças para esta terrível ação". (Ato I, Cena VII, 106-107).

Quando Macbeth retorna com as mãos sujas de sangue, horrorizado pelo ato que praticou, Lady Macbeth contesta: "Não se deve pensar de tal modo nesses atos; de contrário, darão conosco em doidos" (Ato II, Cena II), como que antecipando o que lhe ocorreria mais tarde. Ao saber que ele não havia deixado as adagas no lugar do crime, Lady Macbeth resolve agir: "Oh! Homem fraco! Dá-me os punhais![...] Se o morto ainda sangra, eu mancharei os rostos dos camaristas com o seu sangue, porque este crime tem de parecer praticado por eles". (Ato II, Cena II, 74-79).

Porém, quando retorna, ela demonstra medo pela primeira vez, pois suas mãos estão manchadas de sangue; mas seu coração continua sóbrio. Mesmo depois de cair em si e perceber o que fez, seu autodomínio continua perfeito e ainda continua apoiando o marido.

Depois que Lady Macbeth instaura a coragem sem escrúpulos em seu marido, ele caminha sozinho para seus objetivos. Ele planeja seus atos sem que ela saiba, pois não necessita mais da coragem que ela the transmitia. E mesmo quando é informada das intenções do marido, Lady Macbeth mostra-se pouco interessada, mas não o condena; para ela o trono é o lugar mais apropriado para Macbeth, e acreditava estar ajudando-o a fazer o que ele simplesmente não tinha a ousadia de aventurar. Até mesmo o assassinato de Banquo foi visto por ela como algo que traria paz de espírito ao marido e sugeriu a ação sem remorsos.

Ainda assim é possível encontrar obstinação nela, mas são raros os momentos em que Macbeth necessita de sua ajuda. Podemos considerar que sua última intervenção é na cena do banquete, na qual, com muito esforço, ela "revive" e, serena, encobre o estado de confusão do marido e dispensa os convidados.

Depois desta cena, Lady Macbeth só reaparece no quinto ato, já em estado de loucura. Na cena estão presentes uma dama de companhia e um médico que observam a rainha num monólogo, alheia ao mundo, tentando 
livrar-se da marca do assassinato que antes para ela não era motivo de maiores preocupações - um pouco d'água poderia removê-la - mas que agora era motivo de alucinações: "Desaparece, maldita nódoa, desaparece, vá![...] Nem todos os perfumes da Arábia serão capazes de purificar esta pequena mão! Oh! Oh! Oh![...]" (Ato V, Cena I, 40-60).

Logo após ela se suicida; cena que só é indicada pelos gritos de suas criadas. $\mathrm{O}$ ato do suicídio é visto por Bradley como algo "plenamente de acordo com seu temperamento que, mesmo em seu momento de maior fragilidade, interrompesse de um único golpe a agonia a que sua vida se resumira" (2000, p.292), pois se rogasse por piedade soaria como fraqueza e isso irritaria seu marido que, como muitos autores afirmam, por exemplo, Bradley (ibidem), "os laços amorosos entre os dois se afrouxaram" após a mudança que nele ocorreu e, por isso, Lady Macbeth estaria praticamente abandonada.

\section{A ambição e a loucura de Lady Macbeth}

Assim que conhecemos a personagem de Lady Macbeth, percebemos a força que ela transmite para seu marido, e então ficamos encantados com sua sublimidade, reconhecemos nela uma obstinação e uma grandeza que nos deixa abismados.

Desde o início da peça reconhece-se que, apesar da coragem, a personagem carece de imaginação. Ela, diferentemente de Macbeth, planeja o assassinato de Duncan sem ao menos pensar numa possível falha no ato, e nem mesmo pensa na imagem do rei morto, até que, por um erro de seu marido, ela tem que visualizar o morto e ainda incriminar, com o sangue do rei, os criados embriagados. Para muitos autores é a partir daí que a senhora Macbeth começa a desmoronar:

Quando o assassinato está consumado, a constatação de sua hediondez, primeiramente refletida no semblante de seus hóspedes, se instala em Lady Macbeth com o choque de uma revelação súbita, e, ato contínuo, ela começa a desabar. (BRADLEY, 2000, p.291).

Mas para outros autores, e também defendo essa ideia, devemos analisar a personagem desde o início para realmente compreendermos o que ocorreu. Para Freud (1986), ao se “dessexuar” em função do assassinato, Lady Macbeth esquece-se de seu papel na perpetuação da sua linhagem. 
Então, ao tornar-se rainha, em solilóquio ela demonstra uma desilusão da qual não conseguimos entender a razão: "Nada possuímos; tudo se malogra, quando o nosso desejo realizado não nos dá prazer; é mais seguro ser a pessoa que destruímos, do que viver numa alegria duvidosa, pela sua destruição". (Ato III, Cena II, 6-10).

A percepção da sua desilusão é clara, mas o que tentaremos entender é o que causou essa decepção. Freud questiona se este desengano ocorreu por a personagem, originalmente dócil e feminina, ser forçada a uma situação de tensão muito forte que não conseguiu suportar. Ou, ele se pergunta, "devemos procurar indícios de uma motivação mais profunda, que tornará essa derrocada mais humanamente inteligível para nós?" (FREUD, 1986, p.243).

A predestinação das Bruxas apontava Macbeth como rei, e prometiam que pertenceria aos filhos de Banquo a sucessão ao trono. Mas Macbeth não aceita essa última parte da predestinação e exige da mulher que tenha apenas filhos homens para sucedê-lo. A partir daí coloca-se em destaque a questão da infertilidade de Lady Macbeth, e isso seria a causa da mudança na atitude da personagem. Quando temos a fala de Macduff : "Ele não tem filhos!" (Ato IV, Cena III, 283) ao saber que sua família foi morta por Macbeth, temos algo implícito na frase, pois isso seria o motivo da crueldade do personagem, além de que "também toca no único ponto fraco do caráter insensível de sua esposa”. (FREUD, 1986, p.244).

Devo ressaltar, para uma melhor compreensão, que a peça Macbeth foi feita sob encomenda para o rei Jaime I, que assumiu o trono unificando as coroas da Escócia e da Inglaterra, em razão de a rainha Elisabeth ser estéril: "A ascensão de Jaime I foi vista como uma demonstração da maldição da esterilidade" (FREUD, 1986, p.243), pois Jaime era filho de Maria Stuart, cuja execução teria sido, embora relutantemente, ordenada pela rainha. Essa seria a maldição na qual Macbeth é baseada.

A infertilidade de Lady Macbeth seria, então, uma punição pelos assassinatos cometidos pelo casal, já que a esterilidade impediria a perpetuação de sua progênie e toda sua ambição seria em vão. Freud defende a ideia de que esta infertilidade está ligada ao fato de que Lady Macbeth estaria sob o "assexuamento que exigira dos espíritos do assassinato" (idem, p.244) que, supostamente, num primeiro momento, a ajudou a ter forças para executar o plano sem hesitar, mas que teria consequências não esperadas, as quais resultariam numa profunda desilusão antecedendo a loucura. 
Essas suposições de Freud, a meu ver, esclareceriam o desapontamento de Lady Macbeth, se não fosse por uma questão: o curto espaço de tempo. Shakespeare apresenta a tragédia de Macbeth em apenas sete dias, tempo considerado insuficiente, na minha análise e também de outros autores, para a transformação das personagens, a qual está baseada na insatisfação gerada pela infertilidade de Lady Macbeth. Como afirma Freud, uma semana não seria o suficiente para que esse desapontamento chegasse ao limite e "fizesse a mulher sucumbir e levasse o homem a uma fúria desafiadora" (idem, p.245).

Supõe-se, então, que Shakespeare abreviou Macbeth quando a adaptou das Crônicas da Inglaterra, Escócia e Irlanda, de Raphael Holinshed (1587). $\mathrm{O}$ autor teria abreviado os acontecimentos que ocorreram em uma década para sete dias. Com isso Freud encontra uma explicação mais acessível e compreensível para a mudança em Lady Macbeth: "Não é expressamente mencionado em Holinshed que foi a ausência de filhos que o impeliu a esses caminhos, mas se dá bastante tempo e espaço para esse motivo plausível." (idem, p.245).

Outra suposição, essa trazida pelo próprio Freud na tentativa de resolver o "problema", é a análise de Ludwig Jekels, psiquiatra e psicanalista, que acreditava ter identificado uma técnica que Shakespeare adotava em seus personagens, inclusive em Macbeth e Lady Macbeth:

Ele crê que Shakespeare muitas vezes divide um tipo em duas personagens, as quais, tomadas isoladamente, não são inteiramente compreensíveis e somente vêm a sê-lo quando reunidas mais uma vez numa unidade. Macbeth e Lady Macbeth poderiam estar nesse caso. Ainda sendo, seria destituído de fundamento considerá-la como um tipo independente e procurar os motivos de sua modificação, sem considerar o Macbeth que a completa. [...] Assim, o que ele temia em seus tormentos de consciência, se realiza nela; ela se torna toda remorso e ele, todo desafio. Juntos esgotam as possibilidades de reação ao crime, como duas partes desunidas de uma individualidade psíquica, sendo possível que ambos tenham sido copiados de um protótipo único. (LUDWIG JEKELS apud FREUD, 1986 p.246).

Deste modo, o medo e as alucinações que Macbeth tem no início da peça surgem em sua esposa, levando-a ao suicídio. Macbeth, primeiramente, ouve uma voz que diz que ele não dormirá mais, mas é Lady Macbeth que fica sonâmbula e se contradiz quando tenta limpar suas mãos sujas de sangue, pois, no início, afirmou ser necessário apenas um pouco d'água para limpá-las, e agora não consegue de forma alguma livrar-se das manchas incriminadoras. 
O psiquiatra Ludwig Jekels defende a ideia de que uma única personalidade foi dividida em duas - Macbeth e Lady Macbeth - e no desenrolar das ações o que era encontrado no primeiro agora se encontra no segundo e vice-versa.

Para Harold Bloom, a desilusão de Lady Macbeth estaria relacionada com o afastamento sexual que ocorre entre ela e seu marido.

Será que devemos nos indagar se Macbeth recorre a assassinatos porque sua performance sexual está comprometida? [...] Mas se a hombridade de Macbeth foi tolhida, a perda sexual, se é que ela existe, é causada por ele próprio. [...] Pode ser esse um dos elementos por trás do escárnio expresso por Lady Macbeth, como se a hombridade de Macbeth só pudesse ser recuperada com o assassinato de Duncan. (BLOOM, 2000, p.645).

O autor supõe que a impotência de Macbeth se relaciona com o fato de ele misturar realidade com imaginação, tornando-se desconectado da realidade, por consequência afastando-se também de sua vida erótica, impedindo assim uma possível descendência.

Para reforçar a teoria de que a desilusão de Lady Macbeth é gerada pela não procura sexual do seu marido, Bloom lembra a cena em que Lady Macbeth se diz impossibilitada de matar Duncan com suas próprias mãos pelo fato de ele se parecer com seu pai, e nessa mesma frase ela junta o nome do marido como uma negação de suas qualidades masculinas: "Se o rei no seu sono não se parecesse tanto com meu pai, era eu mesma quem dava cabo nele... Macbeth!” (Ato II, Cena II, 16-18). Numa análise minha, essa menção do nome de Macbeth juntamente com duas figuras relacionadas à paternidade, afasta a ideia de relação matrimonial e o papel de Macbeth não seria de marido, mas de alguém que Lady Macbeth deveria apenas respeitar e obedecer.

Assim teríamos uma explicação sobre a mudança existente na personagem em tão pouco tempo, pois a relação do casal já estaria afetada antes do crime, acentuando-se depois. O domínio que Lady Macbeth exerce sobre o marido, expresso no questionamento da hombridade e da virilidade quando este hesita frente ao homicídio, acontecera por causa de várias frustrações sofridas por ela. Como exemplos, Bloom cita "ambição frustrada, maternidade frustrada e, talvez, prazer sexual frustrado". (BLOOM, 2000, p.648). 
Logo, a paixão entre o casal dependia da realização de um sonho prometido por Macbeth para a esposa, o qual é lembrado por ela nas primeiras cenas juntos: "se eu tivesse jurado lho faria, como vós jurastes que havíeis de executar o vosso projeto..." (Ato I, Cena VII, 75-76).

Considerando essa teoria, a loucura de Lady Macbeth não seria apenas uma consequência da culpa pelo assassinato, mas sim, consequência do afastamento sexual de seu marido que a deixa em segundo plano, motivando o sentimento de fracasso ao triunfar de sua esposa.

\section{Considerações finais}

Talvez Freud tenha razão e não haja argumentos suficientes para explicar como uma personagem tão sublime como Lady Macbeth termina imersa na loucura. Mas, como vimos, é possível levantar várias hipóteses sobre o problema, as quais podemos resumir da seguinte forma: sua fragilidade feminina foi levada a um estado de tensão insuportável; ou então, a ruptura entre os papéis de marido e mulher fez com que Lady Macbeth sucumbisse; ou ainda, uma consciência moral, que nem a própria Lady Macbeth sabia ter, aflora tardiamente fazendo com que ela não consiga suportar o remorso.

Concluímos então que cada tese defendida tem seu valor, e uma não anula a outra, por isso para Freud e para minha própria conclusão, "as tentativas são vãs faces às obscuridades do texto, ao poderoso efeito que a tragédia exerce sobre o espectador". (FREUD, 1986, p.192). O que devemos levar em conta é que toda análise de uma obra é um exercício especulativo que parte de um suporte teórico, e que nenhuma versão é definitiva, estando sujeita a revisões, reavaliações e possíveis mudanças de direção.

\section{Referências}

ARISTÓTELES. A poética de Aristóteles. Disponível em: <http://www.consciencia. org/ aristoteles_poetica.shtml>Acesso em: 24 jul. 2010.

BLOOM, H. Shakespeare: a invenção do humano. Tradução de J.R. O’Shea. Rio de Janeiro: Objetiva, 2000.

BRADLEY, A. C. A tragédia shakesperiana. Tradução de John Russel Brown. São Paulo: Martins Fontes, 2009. 
FREUD, S. Alguns tipos de caráter encontrados no trabalho psicanalítico. Tradução de T. O. Brito, P. H. Britto, C. M. Oiticica. Obras Completas (Vol. XIV, p. 349-377). Rio de Janeiro: Imago, 1986.

HELIODORA, Barbara. Reflexões shakespearianas. Rio de Janeiro: Lacerda, 2004.

SHAKESPEARE, W. Macbeth. Tradução de Domingos Ramos. Porto: Lello \& Irmão Editores, sem Ano.

Recebido para publicação em 16 de março de 2011. Aceito para publicação em 24 de novembro de 2011. 